\title{
Nonlinear Optics Applications: in memory of George I. Stegeman
}

\author{
Gaetano Assanto* \\ Optics Lab, Department of Physics, Tampere University of Technology, 33101 Tampere - Finland \\ NooEL-Nonlinear Optics and OptoElectronics Lab, University Roma Tre, 00146 Rome - Italy
}

Received March 29, 2016; accepted, March 30, 2016; published March 31, 2016

Last May 2015 Prof. George I. Stegeman suddenly passed away at the age of 72 .

With him, the community of nonlinear optics and, in particular, researchers working on guided-wave nonlinear optics, lost one of the most enthusiastic pioneers and scholars in the field.

An insightful scientist, a creative thinker, a motivated researcher, a fantastic teacher, a careful supervisor, a generous man, an outstanding listener, a proud husband and father, George was also a party person, a football and basketball fan, a world traveler. He was loved by his students, collaborators and friends because was able to recognize and appreciate everybody's qualities and talents, from science to sports, from cooking to playing, from story-telling to car-driving. In short, George Stegeman was a gracious man in spite of his prominent role of world-renowned scientist.

I am sure most of the people who came in professional contact with George would agree with at least a few of the attributes I listed above. But only the privileged ones who could share a substantial portion of their life with him can share such a broadband sentiment of affection, respect and admiration. My case is one of them, as I was one of George's PhD students, one of his post-doctors and, later on, one of his friends and (undeserving) colleagues.

George will be missed, with his smile, his simplicity, his understanding of people.

This issue of Photonics Letters of Poland is dedicated to George Stegeman's memory and collects papers from the 2015 edition of the workshop on Nonlinear Optics and Applications (NOA), organized by Prof. Ewa WeinertRączka (West Pomeranian University of Technology in Szczecin) and Prof. Mirosław Karpierz (Warsaw University of Technology) and held in Olsztyn (Poland, September 9-12, 2015).

Since 1992 this workshop, last year at its XIII edition, has been a get-together around George's figure who always played a central role by stimulating, entertaining, supporting and encouraging young and senior researchers and students in the field. Last September we mourned him as we missed his enlightening seminar, his sharp comments, his profound opinions and his challenging questions [1-2]. But most of all, we missed his company.

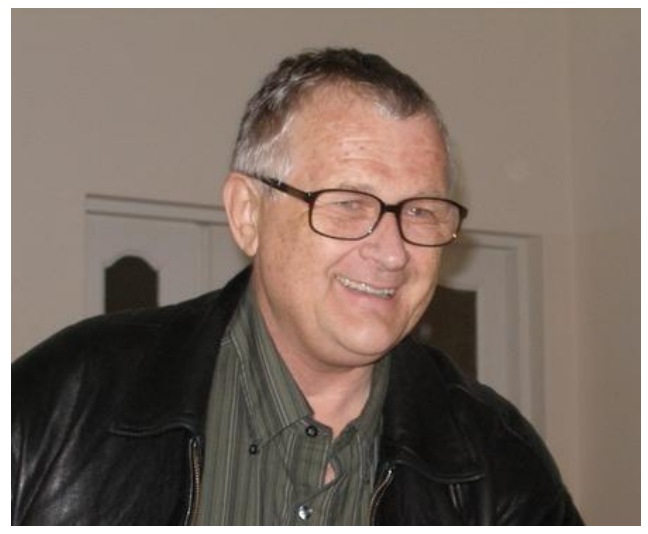

Fig. 1. George I. Stegeman

In the previous NOA workshop, held in Gdańsk (Poland, September 18-21, 2013), George Stegeman presented his excellent book [3] as a prize for the best student presentation (the winner was Bartłomiej Klus from Warsaw University of Technology). In Olsztyn this prize (and George's book) was awarded to Anna Ziołowicz from InPhoTech Ltd.

In this issue the readers find papers on various topics in nonlinear optics, often touching upon subjects which George investigated at some point or another in his densely packed scientific life, either in Toronto (Canada) or in Tucson (Arizona) or in Orlando (Florida). In the latter he spent the final portion of his academic career before retirement.

\section{References}

[1] M.A. Karpierz, G.I. Stegeman, Photon. Lett. Poland 1, 145 (2009).

[2] M.A. Karpierz, G. Assanto, Photon. Lett. Poland 4, 1 (2012).

[3] G.I. Stegeman, R.A. Stegeman, Nonlinear Optics, Phenomena, Materials and Devices (John Wiley \& Sons, Hoboken, New Jersey 2012).

*E-mail: gaetano.assanto@uniroma3.it 